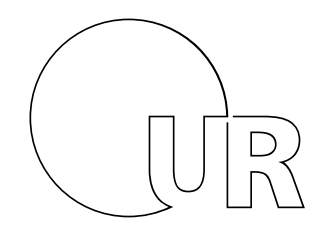

Universität Regensburg
FAKULTÄT FÜR RECHTSWISSENSCHAFT Lehrstuhl für Öffentliches Recht und Völkerrecht

Prof. Dr. Robert Uerpmann-Wittzack robert.uerpmann@jura.uni-regensburg.de http://www.ur.de/rechtswissenschaft/oeffentlichesrecht/uerpmann-wittzack/

Innsbruck, 29. November 2011

\title{
Rechtsfragen und Rechtsfolgen des Beitritts der EU zur EMRK
}

\section{Gliederung}

I. Einleitung

II. Das Abkommen über den Beitritt der EU zur EMRK

III. Konventionsrechtliche Beitrittsvoraussetzungen

IV. Unionale Beitrittsvoraussetzungen

V. Konventionsrechtliche Beitrittsfolgen

VI. Unionale Beitrittsfolgen

VII. Schluss

\section{Thesen}

1. Am 14.10.2011 hat der Lenkungsausschuss Menschenrechte (CDDH) dem Ministerkomitee des Europarates den Entwurf eines „Abkommens über den Beitritt der Europäischen Union zur Konvention zum Schutze der Menschenrechte und Grundfreiheiten" vorgelegt.' Damit tritt der seit vielen Jahren geforderte Beitritt in die Zielgerade ein. Der Beitritt umfasst neben der EMRK die Zusatzprotokolle Nr. 1 und 6, die von allen EU-Mitgliedstaaten ratifiziert wurden. Für die übrigen Zusatzprotokolle wird eine Beitrittsoption eingeräumt.

2. Das Beitrittsabkommen bedarf der Ratifikation durch alle 47 EMRK-Vertragsstaaten und durch die EU. Auf EU-Seite verlangt Art. 218 Abs. 8 UAbs. 2 S. 2 AEUV einen einstimmigen Ratsbeschluss, der von allen EU-Mitgliedstaaten zu ratifizieren ist. Die 27 EU-Mitgliedstaaten müssen also sowohl das Beitrittsabkommen als auch den Ratsbeschluss ratifizieren. Durch das komplizierte Vertragsschlussverfahren erhält das Beitrittsabkommen den Status von Unionsprimärrecht.

\footnotetext{
${ }^{1}$ Dokument CDDH(2011)009.
} 
3. Das Beitrittsabkommen ist vom Grundsatz der Gleichheit aller Vertragsparteien geprägt. Unionsspezifische Sonderregelungen werden auf das unbedingt erforderliche Minimum beschränkt. Namentlich wird die sog. Bosphorus-Rechtsprechung des EGMR zur eingeschränkten Unionsrechtskontrolle mit dem Beitritt hinfällig.

4. Das Beitrittsabkommen bewirkt einen partiellen Beitritt der EU zum Europarat, der so weit reicht, wie es zur Umsetzung eines gleichberechtigten EMRK-Beitritts erforderlich ist. Das gilt namentlich für die Mitwirkung von 18 Abgeordneten des Europäischen Parlaments bei der Wahl von EGMR-Richtern durch die Parlamentarische Versammlung sowie für die Mitwirkung im Ministerrat. Allerdings widerspricht es dem Grundsatz der Gleichheit aller Vertragsparteien, dass die EU im Ministerkomitee gemäß Art. 7 Abs. 2 des Beitrittsabkommens an der Überwachung von EGMR-Urteilen gegen Nicht-EU-Staaten teilnimmt, während ihr dasselbe bei EUMitgliedern versagt bleibt.

5. Art. 3 des Beitrittsabkommens sieht eine Streitgenossenschaft zwischen EU und Mitgliedstaat(en) für den Fall vor, dass ein angegriffener nationaler Akt möglicherweise auf konventionswidrigem Unionsrecht oder dass ein angegriffener Unionsakt möglicherweise auf konventionswidrigem Primärrecht beruht. Dadurch kann die jeweils verantwortliche Vertragspartei am Verfahren beteiligt und durch das Urteil gebunden werden, ohne dass der EGMR Details der unionsinternen Zuständigkeitsverteilung klären muss. Damit sichert die Streitgenosssenschaft auch die Autonomie der Unionsrechtsordnung.

6. Ist die EU in Hinblick auf möglicherweise konventionswidriges Unionsrecht Streitgenosse, muss dem EuGH gemäß Art. 3 Abs. 6 des Beitrittsabkommens in einem Zwischenverfahren die Möglichkeit gegeben werden, die Konventionskonformität zu beurteilen, wenn er dazu noch keine Gelegenheit gehabt hatte. Das Zwischenverfahren gleicht in durchaus stimmiger Weise den unionsspezifischen Nachteil aus, dass Unionsgerichte keine Abhilfe gewähren können, wenn Gerichte des EU-Mitgliedstaates, also einer anderen Vertragspartei, eine Vorlage an den EuGH unterlassen.

7. In der Satzung des EuGH sollte geregelt werden, ob die Sache im Zwischenverfahren automatisch an den EuGH überwiesen wird oder ob es einer Anrufung durch die Kommission bedarf und ob der EuGH ein Gutachten erstattet oder mit den Rechtswirkungen der Art. 264, 267 AEUV entscheidet. Soweit dadurch das Rechtsschutzsystem des AEUV ergänzt wird, ist dies grundsätzlich durch die primärrechtliche Verankerung des EMRK-Beitritts gedeckt.

8. Auf der Ebene der Grundrechtsprechung wurde der EMRK-Beitritt bereits antizipiert. Der EGMR wird die maßgebende Instanz für die Auslegung und Fortentwicklung der in der EMRK garantierten Grundrechtsstandards bleiben. Der EuGH wird sein Bemühen um einen hochwertigen unionalen Grundrechtsschutz tendenziell weiter verstärken, und er wird sich auch bei der Auslegung der Grundrechte-Charta weiterhin an der Rechtsprechung des EGMR orientieren. Möglicherweise werden von der modernen Grundrechte-Charta in Zukunft verstärkt Impulse zur Fortentwicklung der Straßburger Rechtsprechung ausgehen. Dies geschieht jedoch unabhängig vom EMRK-Beitritt der EU.

9. Mit dem Beitritt der EU wird die EMRK zum gemischten Abkommen. Im Anwendungsbereich des Unionsrechts nimmt die EMRK in den Mitgliedstaaten am Anwendungsvorrang des Unionsrechts teil, doch ist dies zu vernachlässigen, weil den parallelen Unionsgrundrechten ohnehin Anwendungsvorrang zukommt. Auch außerhalb des Anwendungsbereichs des Unionsrechts ist eine Vorabentscheidung des EuGH gemäß Art. 267 AEUV zulässig, doch sollten Richtervorlagen insoweit in Hinblick auf die Gerichtsbarkeit des EGMR unterbleiben.

10. Mit dem insgesamt gelungenen Beitrittsabkommen unterwirft sich die staatsähnliche EU einer externen Menschenrechtskontrolle, wie sie für europäische Verfassungsstaaten selbstverständlich ist. Ansonsten werden die Beitrittsfolgen überschaubar bleiben. 